\title{
Repensando a relação entre Ciência e Religião no processo de ensino e aprendizagem
}

\author{
Rethinking the relationship between Science and Religion in the teaching \\ and learning process
}

\author{
William Rossani dos Santos (william_rossani@hotmail.com) \\ PEHT - IG/Universidade Estadual de Campinas \\ Rebeca Chiacchio Azevedo Fernandes (rebeca_chiacchio@ hotmail.com) \\ DTPP/Universidade Federal de São Carlos \\ PEHCT - IG/Universidade Estadual de Campinas
}

\begin{abstract}
Resumo: Na literatura científica as relações entre Ciência e Religião ainda são ambíguas devido as diferentes interpretações de relacionamentos possíveis entre ambos os campos. Na tentativa de contribuir no estudo de tal temática, buscamos compreender as possíveis relações existentes entre Ciência e Religião e a forma mais adequada de tratá-las na educação científica, considerando o atual contexto da Sociedade da Informação. Para tanto, o procedimento metodológico desdobrou-se em duas etapas: uma primeira etapa, visando a categorização das relações entre Ciência e Religião em seis obras da literatura sobre a temática; e uma segunda etapa, pautada na análise comparativa entre diferentes Modelos Conceituais de vertente construtivista, buscando identificar seu tratamento de modo prático. Os resultados indicam três relações possíveis entre Ciência e Religião, que envolvem o Conflito, a Síntese e o Diálogo, sendo esta última a que mais se adequa aos Modelos Conceituais aceitos na atualidade, centrados nos processos socioculturais do conhecimento. Dentre os três modelos analisados, verificou-se que a adoção do Modelo de Perfil Conceitual e do Construtivismo Contextual, podem ser adequados para o tratamento pedagógico mais dialógico entre Ciência e Religião, ao contrário do Modelo de Mudança Conceitual, focado na cognição individual e na substituição integral dos conhecimentos prévios pelos conhecimentos científicos.
\end{abstract}

Palavras-chave: Ciência e Religião; Modelos Conceituais; Ensino de Ciências.

Abstract: In the scientific literature, the relationship between Science and Religion is still ambiguous due to the different interpretations of possible relationships between both fields. In an attempt to see the various aspects that constitute them, we seek to understand the possible existing relations between Science and Religion and the most appropriate way to deal with them in science education, considering the current context of the Information Society. For this, the methodological procedure was divided into two stages: a first stage, aiming at categorizing the relations between Science and Religion in six works of literature on the theme; and a second stage, based on a comparative analysis between different Conceptual Models with a constructivist approach, seeking to identify their treatment in a practical way. The results indicate three possible relations between Science and Religion, which involve Conflict, Synthesis and Dialogue, the 
latter being the one that best suits the Conceptual Models accepted today, centered on the social and cultural processes of knowledge. Among the three models analyzed, it was found that the adoption of the Conceptual Profile Model and Contextual Constructivism, may be suitable for the more dialogical pedagogical treatment between Science and Religion, in contrast to the Conceptual Change Model, focused on individual cognition and integral replacement of previous knowledge by scientific knowledge.

Keywords: Science and Religion; Conceptual Models; Science Teaching.

\section{INTRODUÇÃO}

A indissociabilidade entre Ciência e Religião marcam profundamente a História da Ciência, tanto pelo empreendimento histórico da prática científica por religiosos que não dissociam sua fé pessoal das explicações do mundo natural, como pela instauração de campos da Ciência específicos para o estudo de fenômenos religiosos, como é o caso da Ciência da Religião e a incorporação da racionalidade científica no território religioso para a análise de documentos sacros (eg. método histórico-crítico). Entretanto, ainda que haja uma ligação histórica e epistêmica entre esses dois domínios, as discussões teóricas sobre tal relação ainda é controversa, pois nem sempre os consideram de forma harmoniosa.

No debate acadêmico sobre as relações possíveis de compatibilidade e incompatibilidade da Religião e da Ciência, encontramos uma variedade de autores que trouxeram profundas contribuições sobre essas questões, como Brian Woolnough (1996), Harold Turner (1996), Hugh Lacey (1996), Martin Mahner e Mario Bunge (1996a, 1996b), Michael Poole (1996) e Tom Settle (1996). Entre os principais argumentos em defesa da compatibilidade, podemos encontrar a tese de multidimensionalidade de visões de mundo, que pode variar em sua aplicação de acordo com a natureza de cada tipo de conhecimento (POOLE, 1996; WOOLNOUGH, 1996). A esse respeito, Woolnough (1996, p. 180) destaca que "diferentes formas de conhecimento, diferentes descrições são apropriadas em contextos diferentes. Cada um pode ser verdadeiro, cada um pode ser válido, cada um pode ser compatível com o outro". O autor chega a afirmar que "não existe um único critério para a verdade; a verdade tem significados bastante diferentes em diferentes contextos" (WOOLNOUGH, 1996, p. 179). 
Acreditamos que esse ponto pode ser válido em certa medida, desde que se reconheça a validade social de cada conhecimento e sua aplicação na sociedade em que vivemos, pois a relativização de todos os conhecimentos com o mesmo valor de verdade pode fazer com que não restem padrões comuns nos quais se possa desafiar a verdade de afirmações pseudocientíficas, por exemplo (MAHNER; BUNGE, 1996b).

Ressalta-se que, mesmo com a defesa da compatibilidade por este e outros autores, há uma ampla aceitação entre eles das diferenças entre os dois campos, embora não as entendam como inconciliáveis. Para Lacey (1996), por exemplo, as diferenças entre Ciência e Religião podem ser entendidas como tensões construtivas e não como incompatibilidades radicais.

Do outro extremo, encontramos os elementos de real divergência. Para alguns pesquisadores, a Ciência e Religião são dois domínios antagônicos. Segundo Jones (1994), muitos entendem que "a Religião e a Ciência são reinos separados e mutuamente excludentes do pensamento humano, cuja apresentação no mesmo contexto leva a mal entendimentos tanto da teoria científica como da crença religiosa" (JONES, 1994, p. 186). Esse é o caso de autores como Mahner e Bunge (1996a; 1996b). Para os teóricos, ao se investigar tal relação, há que se ter em mente que "a compatibilidade entre Ciência e Religião é matéria de metodologia e metafísica, não de história ou biografia" (MAHNER; BUNGE, 1996a, p. 112). Isso significa que, mesmo entre os cientistas adeptos a uma certa crença religiosa, há um amplo reconhecimento das diferenças ontológicas, metafísicas e epistemológicas de cada campo, principalmente se entendermos que os objetos da Ciência possuem fundamentos naturalistas em termos do materialismo, enquanto a Religião, pelo contrário, incorpora muitos elementos supranaturais, como é o caso das entidades imateriais e sobrenaturais, que não podem ser validadas pelo instrumental científico existente (MAHNER; BUNGE, 1996b). Os autores destacam que "não há sentido em fazer estudos empíricos, a menos que pressupomos a verdade do naturalismo" (MAHNER; BUNGE, 1996a, p. 190). Portanto, para ambos, a Religião e a Ciência não são apenas diferentes, mas mutualmente incompatíveis quando se compara seus elementos de cognoscibilidade.

Fora dos debates estritamente acadêmicos essa problemática não é diferente, como no tratamento das relações entre Ciência e Religião no âmbito escolar. Isso porque os saberes prévios do alunado, incluindo as suas crenças religiosas, têm se mostrado em 
dissonância com as ideias científicas (SEPULVEDA, 2003; ALMEIDA, 2012; FIGUEIREDO; SEPULVEDA, 2018). Essa evidência decorre, por sua vez, do fato de que as concepções científicas não são intuitivas, mas apreendidas, o que incide no choque inicial com outros saberes, e na necessidade da educação científica em iniciar os "estudantes em uma nova maneira de pensar e explicar o mundo natural, que é fundamentalmente diferente daquelas disponíveis no senso-comum" (MORTIMER, 1996, p. 24).

As discussões construtivistas que foram sendo elaboradas para explicar a relação entre ideias prévias e científicas trouxeram a clara necessidade de se repensar as relações estabelecidas por ambas as instâncias e de se refletir acerca dos elementos que constituem as noções cotidianas dos estudantes, inclusive as crenças religiosas que também fazem parte do arsenal prévio que estes trazem consigo de suas culturas de origem. No entanto, como nos indica Duschl (1994, p. 206), "sem qualquer investigação ou análise que ajude a promover um entendimento tanto das fontes dessas concepções quanto das estratégias envolvidas na sua utilização, a pesquisa é simplesmente descritiva".

Neste sentido, pensar essa problemática a nível epistemológico, cultural, e didáticometodológico é essencial, não só para identificar, mas também para transformar a relação de conflito entre os diferentes tipos de conhecimentos encontrados na literatura, buscando caminhos viáveis de se trabalhar tais questões nas salas de aula, em especial, no ensino de ciências. A fim de contribuir nesse processo, o objetivo da presente investigação é o de classificar as possíveis relações entre Ciência e Religião e analisar as formas mais apropriadas de tratá-las na educação científica com base nos Modelos Conceituais disponíveis.

\section{PROCEDIMENTO METODOLÓGICO}

O procedimento metodológico empregado na presente investigação constituiu-se de um exame de literatura sobre a temática "Relações entre Ciência e Religião", acompanhado de um estudo comparativo entre diferentes Modelos Conceituais para a análise da aplicação dessas relações. Para tanto, os documentos de análise consistiram de um duplo formato de pesquisa: para a investigação das tipologias classificatórias do relacionamento entre Ciência e Religião, foram utilizadas obras completas que 
discutissem e categorizassem as possíveis relações entre ambas as áreas, totalizando seis bibliografias (DEMBSKI, 1999; BARBOUR, 2004; RUSSEL, 2004; MCGRATH, 2005; HAUGHT, 2006; EUVÉ, 2009); e para uma análise pedagógica desta problemática, foram analisados artigos científicos com enfoque em Modelos Conceituais para o ensino de ciências (GUNSTONE; CHAMPAGNE; KLOPFER, 1981; POSNER et al., 1982; GAULD, 1986; HEWSON; THORLEY, 1989; WHITE; GUNSTONE, 1989; BISHOP; ANDERSON, 1990; CHI, 1991; LINDER, 1993; MORTIMER, 1993; CARAVITA; HALLDÉN, 1994; SETTLAGE, 1994; DEMASTES-SOUTHERLAND; SETTLAGE; GOOD， 1995; EBENEZER; GASKELL, 1995; COBERN，1993，1994，1996; MORTIMER，1996; EL-HANI; BIZZO, 2002).

Na primeira etapa de análise, além de focalizar a categorização da relação entre Ciência e Religião por cada uma das 6 publicações, buscamos identificar pontos de encontros comuns entre essas categorias para sintetizá-los em outras categorias pertinentes à nossa análise comparativa — precisamente pela variedade de tipologias encontradas (duplas, triplas e quadruplas); enquanto a segunda etapa da pesquisa buscou compará-las com as evidências de Modelos Conceituais elaborados por diferentes correntes construtivistas (Modelo de Mudança Conceitual, Construtivismo Contextual e Modelo de Perfil Conceitual), para compreender qual das subcategorias analisadas se aproximam de um processo de ensino e aprendizagem com resultados efetivos na educação científica ao se trabalhar conjuntamente os tópicos religiosos e científicos.

\section{RESULTADOS E DISCUSSÃO}

\subsection{Classificando as possíveis relações entre Ciência e Religião}

De acordo com a literatura disponível, foi possível identificarmos uma série de tipologias viáveis para enquadrar a relação entre Ciência e Religião no que se refere aos seus pontos de encontro e dissidência. Barbour (2004), por exemplo, apresenta uma tipologia quádrupla para classificar a grande variedade de maneiras pelas quais a Ciência e Religião podem se relacionar, estas são: Conflito, Independência, Diálogo e Integração. Essas categorias podem corresponder às seguintes características: 1 . Conflito: a incompatibilidade entre a fé religiosa e as ideias científicas; 2. Independência: a compreensão de que os domínios religiosos e científicos são estranhos, mas podem coexistir entre si, desde que mantenham uma distância segura um 
do outro; 3. Diálogo: uma atitude de respeito e parceria entre Ciência e Religião, em que a reflexão crítica se paute nas fronteiras que a Ciência é incapaz de sobrepor e em tópicos que a Religião é incapaz de resolver; 4. Integração: representando o sincretismo entre ambos os saberes, onde um domínio abarcaria o outro, como no caso da Teologia Natural, da Teologia da Natureza e da Síntese Sistemática.

Outras categorias possíveis são indicadas por John Haugth (2006). O autor propõe três tipos de relações possíveis entre Religião e Ciência, a saber: Oposição, Separatismo e Engajamento. A primeira relativa ao antagonismo de visões; a segunda referente ao fato de que Ciência e Religião são tão radicalmente diferentes em seus métodos que não haveria razão lógica para o estabelecimento de um conflito; e a terceira, partindo do entendimento de que um saber contribuiria para o fortalecimento do outro de forma subsequente.

Além dessas, temos uma multiplicidade de categorias descritas por outros autores, mas que não destoam substancialmente entre si quanto às suas finalidades, apenas quanto a terminologia empregada, como nos casos de: Russell (2004) com as categorias de Oposição, Síntese e Juízo Suspenso; Mcgrath (2005), com a classificação dupla: Modelo em Confronto e Modelo de Diálogo; a divisão quádrupla de Dembski (1999) abrangendo o Modelo de Compartimentalização, Modelo de Complementaridade, Modelo de Conflito e Modelo de Suporte Mútuo; e Euvé (2009), com a proposição de três relações: Oposição, Síntese e Separação.

De modo geral, têm-se, pelo menos, três categorias possíveis para poder-se analisar as relações entre Ciência e Religião, que admitiremos para a realização de nossa análise comparativa: uma primeira referindo-se ao Conflito, que demarca as fronteiras de contato da Ciência e da Religião; uma segunda, circunscrevendo a Síntese ou o sincretismo entre os domínios científicos e religioso; e, uma terceira, tendo em vista o Diálogo, que compreende a independência de cada domínio, por suas diferenças intrínsecas, mas abre espaço para a convivência harmoniosa entre eles, a partir da negociação de sentidos.

Com base nessas três tipificações genéricas (Conflito, Sintese e Diálogo) sintetizadas a partir da variedade de categorias descritas pelos autores supracitados, foi possível as correlacionarmos com os Modelos Conceituais propostos por investigadores 
Edição Especial: I SSAPEC - Simpósio Sul-Americano de Pesquisa em Ensino de Ciências

ISSN: 2595- $4520 \quad$ Vol. 4, n. 3. 2021

que estudam a relação entre ideias prévias e conhecimento científico, para verificarmos a sua aplicabilidade no contexto pedagógico.

\subsection{O tratamento das relações entre Ciência e Religião a partir dos Modelos} Conceituais

O Modelo de Mudança Conceitual elaborado por Posner, Strike, Hewson e Gertzog (1982), explicita que, para que um aprendiz possa efetivamente aprender um novo conceito, é necessária a substituição integral de uma concepção prévia (alternativa ou espontânea) que o aluno possui por uma concepção científica correta. De acordo com os autores, essa substituição seria possível através dos diferentes conflitos cognitivos que iriam sendo gerados no processo de ensino e aprendizagem, fazendo com que o aluno progressivamente ampliasse seus conhecimentos científicos a partir da inadequação dos conceitos prévios utilizados na resolução de determinados problemas.

A estrutura teórica do modelo se sustenta mediante quatro condições fundamentais, necessárias para a acomodação de um novo conceito pelos estudantes: inteligibilidade, plausibilidade, fertilidade e insatisfação — basilarmente ancoradas na Epistemologia Genética piagetiana, que subentende a evolução do conhecimento por meio de fases pré-definidas em um continuum de reequilibração de conceitos, e na nova filosofia da Ciência, sob os pressupostos kuhnianos do desenvolvimento científico (MORTIMER, 1996; EL-HANI; BIZZO, 2002).

Ao situarmos as crenças religiosas como parte do arcabouço das concepções prévias e alternativas dos estudantes na perspectiva trazida por esse modelo, seria de se esperar que, para que estes pudessem compreender os tópicos científicos seria necessária a substituição completa de suas crenças pessoais pelas ideias aceitas pela comunidade científica. Isso pode ser evidenciado nos argumentos de Hewson e Thorley (1989), dois dos grandes proponentes do modelo, quando declaram que "concepções conflitantes não podem ser simultaneamente plausíveis para uma pessoa” (p. 543). No entanto, como pôde ser demonstrado por outros autores, os pressupostos teóricos presentes neste modelo se mostraram pouco efetivos, pois decorriam em graves limitações e, em toda aplicação prática, malogravam em alguma medida, como evidenciam Gunstone, Champagne e Klopfer (1981); Gauld 1986; White e Gunstone (1989); Bishop e Anderson (1990), Settlage (1994) e Demastes-Southerland, Settlage e 
Good (1995); Cobern (1996); Mortimer (1996) e El-Hani e Bizzo (2002). Uma das consequências negativas mais evidenciadas na tentativa de mudança conceitual era a de que, após algum tempo de aparente compreensão científica, os estudantes retornavam às suas concepções anteriores (GAULD, 1986; WHITE; GUNSTONE, 1989).

Ao analisar o Modelo de Mudança Conceitual, Mortimer (1996), demonstra que, para além dos conflitos cognitivos, a existência de lacunas também devem ser alvos de preocupação no processo de aprendizagem, pois "a falta de informações para interpretar os resultados de um experimento é obstáculo maior que o conflito entre as ideias dos estudantes e os resultados" (MORTIMER, 1996, p. 24). O autor também critica os aspectos psicológicos e filosóficos do modelo por serem equivocados teoricamente e se contradizerem de forma empírica. Dos aspectos psicológicos, Mortimer (1996, p. 24) ressalta que "essas propostas não conseguem tirar todas as consequências da teoria que parece inspirá-las", além de apontar que as características do sujeito epistêmico piagetiano, de onde esses modelos se orientam, não prevalecem na vida cotidiana. Quanto aos aspectos filosóficos, o autor é incisivo ao argumentar sobre o equívoco de se tentar transpor os modelos kuhnianos relativos às revoluções científicas para as situações de ensino e aprendizagem. Em suas palavras,

O novo campo das ciências físicas, que lida com fenômenos complexos, como sistemas auto-organizadores, sistemas caóticos, etc., teria nascido em consequência de uma crise em teorias bem estabelecidas como, por exemplo, a mecânica quântica? Este novo campo teve que superar alguma tradição bem estabelecida para emergir? Parece não haver respostas positivas para essas questões. A chamada Física dos sistemas complexos nasceu mais como o resultado de se voltar a atenção para alguns sistemas que, por sua complexidade, eram impossíveis de serem estudados antes dos computadores se tornarem parte do cotidiano dos laboratórios, uma vez que eles permitiram que se lidasse com um grande número de cálculos e com simulações (Davis, 1989). Esse novo campo nasceu, portanto, como um desenvolvimento paralelo, baseado, certamente, em novo paradigma, mas que não teve que derrotar seus antecessores.

Assim,

Mesmo que o modelo de revolução científica pudesse ser aplicado a qualquer
mudança conceitual na ciência, sua transposição para o processo de ensino-
aprendizagem desconhece as diferenças profundas entre um processo que
ocorre dentro de uma cultura científica e outro, que é justamente um processo
de "enculturação" (Driver, Asoko, Leach, Mortimer \& Scott, 1994)
(MORTIMER, 1996, p. 27).

Por outro lado, White e Gunstone (1989) destacam a fraqueza de aspectos como os de insatisfação dos conceitos prévios para se alcançar os conceitos científicos, pois, 
se a ideia de insatisfação surge da demonstração de que a crença tem desvantagens reais no mundo além da sala de aula formal, isso não teria muito valor para para a maioria das pessoas que não serão cientistas em atividade. Em outras palavras, seria frívolo e de pouca utilidade, em termos de convencimento científico, que os estudantes soubessem "que o calor está relacionado à energia cinética das partículas e não é um fluido" (WHITE; GUNSTONE, 1989, p. 580), por exemplo, o que não constituiria uma insatisfação concreta. Essas afirmações vão ao encontro do argumento que Cobern (1996) apresenta quando elucida que as concepções cotidianas dos estudantes diferem das concepções científicas porque elas servem a diferentes objetivos.

Devido aos constantes fracassos e críticas ligadas à mudança conceitual, outros modelos foram sendo propostos e atualizados (CHI, 1991; LINDER, 1993; CARAVITA; HALLDÉN, 1994; EBENEZER; GASKELL, 1995; MORTIMER, 1993, 1996; COBERN, 1996), ao demonstrarem a possibilidade da coexistência de dois significados para o mesmo conceito, os quais são acessados no contexto adequado. Aqui daremos ênfase ao Modelo de Perfil Conceitual elaborado por Mortimer (1993; 1996), por partir dos estudos citados; e ao Construtivismo Contextual, de Cobern $(1993 ; 1996)$, que ao invés de apenas reconhecer a cognição individual no processo de aprendizagem, também destacam a natureza social do conhecimento científico.

Segundo Mortimer (1993; 1996), ao contrário do que pressupõe o Modelo de Mudança Conceitual, no processo de aprendizagem não ocorre uma substituição da concepção alternativa "errada" pelo conceito científico "correto"; ambos passam a ser parte do arsenal de conhecimentos de um determinado indivíduo, que utilizará o conceito adequado em um dado contexto. Essa ideia vai ao encontro do que Matthews (1994) explicita ao dizer que:

\begin{abstract}
Subjetivamente, dentro de um indivíduo, todos os tipos de visões de mundo mutuamente inconsistentes podem coexistir. Os indivíduos frequentemente não têm consciência das contradições. Mesmo quando as contradições entre compromissos intelectuais são aparentes, os indivíduos podem viver com enormes quantidades de dissonância cognitiva (MATTHEWS, 1994, p. 185).
\end{abstract}

Com efeito, a principal inspiração para a elaboração de seu modelo parte da "noção de perfil epistemológico" de Bachelard que reconhece que "uma única doutrina filosófica não é suficiente para descrever todas as diferentes formas de pensar quando se tenta expor e explicar um simples conceito" (BACHELARD, 1984 apud MORTIMER, 
1996, p. 29) ${ }^{1}$. Portanto, fica claro nessa visão que a construção do conhecimento não é percebida como um constante processo de trocas conceituais cada vez mais refinado, mas como um apanhado de conhecimentos de diferentes naturezas que podem se relacionar independente e simultaneamente (MORTIMER, 1993; 1996).

A chave desse modelo encontra-se em duas premissas centrais que divergem dos princípios psicológicos e filosóficos do Modelo de Mudança Conceitual: 1. a possibilidade de que uma pessoa possa usar diferentes formas de pensar em diferentes domínios; e 2. a possibilidade de que a construção de uma nova ideia possa, em algumas situações, ocorrer independentemente das ideias prévias e não necessariamente como uma acomodação de estruturas conceituais já existentes (MORTIMER, 1996).

Transferindo essa concepção para a relação entre Ciência e Religião, compreende-se que ambas as esferas podem coexistir e serem usadas em contextos distintos, desde que mantenham sua autonomia enquanto duas culturas díspares, com suas próprias linguagens sociais, funções, ontologias e conceitos.

De forma semelhante, o Construtivismo Contextual de Cobern $(1993,1996)$, procura incorporar "o papel da cultura no desenvolvimento e na validação das crenças individuais e procura inserir a ciência no contexto sociocultural, considerando-a uma segunda cultura para os aprendizes" (EL-HANI; BIZZO, 2002, p. 52). A partir dessa perspectiva, os alunos podem aprender os conhecimentos científicos já tendo em sua estrutura cognitiva outras linguagens e culturas, que os auxiliarão a fazer a mediação entre o conhecimento e o mundo. Com efeito, suprimir as concepções alternativas dos estudantes, "significaria suprimir o pensamento de senso comum e seu modo de expressão, a linguagem cotidiana. Uma expectativa irreal e inútil” (MORTIMER, 1996, p. 26).

No que tange a esses dois níveis de conhecimento, prévio e científico, há que se entender aqui a grande diferença que acaba por distanciar no ensino de ciências as estratégias de se buscar a compreensão (ter o domínio de uma noção) e a crença (aceitar uma noção como válida e verdadeira) dos estudantes. Ou seja, um conceito “completamente compreendido por uma pessoa pode ser por ela rejeitado, por não ter

\footnotetext{
${ }^{1}$ De acordo com Mortimer (1996), as diferenças fundamentais entre o modelo proposto por Bachelard e o seu, são: o acréscimo da distinção entre características ontológicas e epistemológicas de cada zona do perfil; da tomada de consciência pelo estudante de seu perfil conceitual; e o foco nos compromissos epistemológicos e ontológicos dos indivíduos em detrimento dos níveis pré-científicos determinados por escolas filosóficas.
}

Recebido em: 18/01/2021

Aceito em: 24/02/2021 
força e alcance no contexto de sua visão de mundo" (EL-HANI; BIZZO, 2002, p. 57). A esse respeito, Cobern (1994) defende a importância de não apenas dar atenção ao processo de compreensão dos conhecimentos científicos pelos estudantes, mas também entender e se aprofundar em suas crenças pessoais, pois, para o autor, no que tange ao tratamento de questões científicas, "a crença é o lugar onde a instrução deve começar" (COBERN, 1994, p. 587). No limite, o autor chega a enfatizar que a modificação das crenças dos estudantes também pode se constituir como uma meta de ensino, uma vez que a estratégia de aprimoramento da compreensão e a estratégia de fazer com que as ideias científicas sejam críveis, constituem dois processos distintos.

Em linhas gerais, a perspectiva sociocultural do conhecimento presente nesses dois modelos deixa claro que, para que se possa compreender a complexidade do processo de enculturação na educação científica, é fundamental a planificação de estratégias conceituais, epistemológicas, ontológicas e metodológicas por parte do professor que orientem o processo de aprendizagem e a forma pelas quais os estudantes percebem suas culturas. No entanto, essa planificação só pode ter êxito se tiver em seu requisito a própria concepção docente da compatibilidade e incompatibilidade entre diferentes tipos de conhecimentos divergentes e a sua compreensão dos modelos conceituais que lidam com o relacionamento de diferentes epistemologias.

Entendemos que uma postura sociocultural efetiva na educação científica depende de uma transformação tanto no processo de ensino, como no processo de aprendizagem. E, embora, o ensino e a aprendizagem sejam dois processos distintos, cujas peculiaridades devem ser reconhecidas para o desenvolvimento de um trabalho pedagógico de qualidade, estes devem estar em profunda conexão por suas metas constitutivas correlatas. Como assinala Roldão (2010, p. 55), "não se trata de substituir o bom ensino por uma mescla de ensino intencional com aprendizagem autônoma, que esbate o sentido de ambos”. Antes, trata-se de assumir o verdadeiro ensino como "aquele que se orienta intencionalmente para a aprendizagem pretendida, não sendo ensino se a promoção intencional da aprendizagem, na sua complexidade, não estiver contemplada" (ROLDÃO, 2010, p. 55). Nessa perspectiva, ambos os processos estarão sendo considerados intencionalmente na medida em que o ensino terá ação estratégica de promover a aprendizagem e aprendizagem terá como mediação as estratégias do próprio ensino. 


\subsection{A aplicação das categorias relacionais entre Ciência e Religião nos Modelos}

\section{Conceituais}

Ao tomarmos os resultados do Modelo de Mudança Conceitual como base para o trabalho pedagógico no ensino de ciências e buscarmos alinhá-los com as três categorias possíveis entre Ciência e Religião (Conflito, Síntese, Diálogo), anteriormente definidas, podemos notar que a categoria Conflito - que considera a demarcação das fronteiras de contato da Ciência e da Religião — é a que mais se aproxima de seus princípios basilares, uma vez que as crenças religiosas não teriam espaço de compartilhamento ao lado das ideias científicas. Por outro lado, ao analisarmos essas mesmas categorias com o Modelo de Perfil Conceitual e o Construtivismo Contextual verificamos que a tipologia compreendida como Diálogo - que considera a independência de cada domínio, mas tendo em vista a possibilidade da convivência harmoniosa entre ambos - é a que mais se aproxima dos princípios dos dois modelos, por permitirem a coexistência de diferentes tipos de culturas e conhecimentos, sem recair na dimensão do sincretismo (Síntese).

Também levando em consideração a constatação pelas Ciências Sociais de um giro dialógico ocorrido mundialmente desde as últimas décadas do século $\mathrm{XX}$, que modificou diferentes aspectos socioculturais e rompeu com processos anteriormente estabelecidos, pode-se notar que, além da inconsistência teórica e empírica do Modelo de Mudança Conceitual já comentadas, seus preceitos já não dão conta de responder as demandas de uma sociedade cada vez mais multicultural, mundializada e informatizada como a que vivemos atualmente, que exige posturas cada vez mais dialógicas e centradas nas interações intersubjetivas e não apenas na cognição individual (FLECHA, GÓMES; PUIGVERT, 2001; AUBERT et al., 2008; MELLO, BRAGA; GABASSA, 2014). Outras justificativas, neste mesmo sentido, são as de que, as implicações da crise das autoridades tradicionais e a descentralização do conhecimento desse novo contexto agora possibilita que os indivíduos façam escolhas conscientes em diferentes âmbitos de suas vidas, sem serem coagidos por uma autoridade externa, além de poderem consensuar e negociar decisões para a viabilidade da democracia (HABERMAS, 1987; FLECHA, GÓMES; PUIGVERT, 2001; AUBERT et al., 2008).

Neste sentido, o Modelo de Perfil Conceitual e o Construtivismo Contextual tem um potencial maior para responder as demandas de espaços e interações mais 
dialógicas, cercada por diferentes culturas, entre elas a científica e a religiosa. Ademais, como alguns autores indicam, o Diálogo pode ser enxergado como um território movido tanto pelo consenso quanto pelo dissenso, contribuindo para o estabelecimento de desacordos de forma negociada, sem precisar permanecer nos horizontes de conflito (HABERMAS, 1987; FLECHA, 1997; AUBERT et al., 2008). Bachelard (1978) é incisivo ao destacar que "se duas pessoas desejam verdadeiramente entender uma a outra, ambas devem primeiro contradizer-se", pois "a verdade é filha da discussão e não da simpatia" (BACHELARD, 1978, p. 06). Essa assertiva leva em consideração que a descoberta da "verdade" se dá de forma dialógica e polêmica, isto é, pelo confronto de ideias e crítica mútua, cujo modelo é o próprio funcionamento e a dinâmica de uma comunidade científica, que pode ser aplicado a todos os outros âmbitos, como aos debates educacionais.

Flecha (1997) também afirma que

O acordo é imprescindível para alcançar pautas que nos permitam uma vida coletiva em condições plenamente libertárias e equitativas. Entretanto, o desacordo também é necessário. As normas existentes são resultado de consensos insuficientemente igualitários: temos que discordar delas para alcançarmos outras, frutos de um melhor consenso. (FLECHA, 1997, p. 79, tradução nossa).

Essa concepção que se distancia do conflito, mas busca validar o desacordo dialógico, é bastante pertinente, pois possibilita o aumento de chance que os sujeitos têm em se defrontarem com um conjunto maior de possibilidades, complexificando e ampliando a compreensão das situações problematizadas.

\begin{abstract}
Ao sermos expostos a ideias diferentes nunca mais somos os mesmos, pois temos que confrontar nossos pontos de vista com os de outros, modificandoos, seja de modo a defender posições anteriores de outra forma ou de modo a substituí-las por outras. De qualquer maneira nossas opiniões apresentam o potencial de se tornarem em geral mais consistentes ao entrarem em contato prolongado com outras diferentes dela e que a ela, muitas vezes, se opõem. (DORVILLÉ, 2010, p. 287).
\end{abstract}

Neste sentido, a consideração de teorias como as da Aprendizagem Dialógica, que considera o Diálogo como uma chave de entendimento com vistas a alcançar maiores acordos possíveis sobre algum aspecto da realidade, pela validade dos argumentos e não pela pretensão de poder, se coloca como um elemento fundamental para que se logre espaços que ampliem as aprendizagens de todos e todas de forma democrática no interior da sociedade contemporânea (AUBERT et al., 2008). Seus 
princípios indicam que a aprendizagem resultante de interações dialógicas pode ser capaz de potencializar e tornar mais complexos os conhecimentos dos indivíduos, além de transformar seus contextos e a si mesmos.

Por fim, ressaltamos que, apesar de compreendermos o relacionamento da Religião e da Ciência como duas áreas passíveis de diálogo, estamos de acordo com diferentes teóricos que explicitam que o papel da Religião no ensino de ciências não deve ultrapassar o debate de ideias entre diferentes concepções culturais, e, quando necessária, deve circunscrever apenas na problematização de seus aspectos históricos, filosóficos e sociológicos (MAHNER; BUNGE, 1996; CUNHA, 2006, 2013). Essa posição é importante de ser salientada, pois se alinha com a preocupação de uma escola que se propõe laica, democrática, plural e contrária a tentativa ideológica de incorporação proselitista de crenças particulares, como é o caso das inúmeras investidas a favor da inserção do Criacionismo como uma concepção alternativa no currículo científico, que claramente se opõe à ampliação de uma concepção multicultural real da qual estamos propondo, implicando, inclusive, na distorção das especificidades de cada modalidade de conhecimento.

Como enfatizado a princípio, as múltiplas visões de mundo sobre um determinado fenômeno podem ser profícuas para a ampliação de diferentes modos de se pensar, potencializando iniciativas no sentido da reflexão e investigação, essenciais na educação científica. Todavia, compreender a demarcação de cada um dos campos de conhecimento humano por sua especificidade e natureza para responder determinadas perguntas, é crucial para evitar distorções que podem ser prejudiciais à singularidade de cada domínio. Afinal, como Lacey (1996), Poole (1996) e Woolnough (1996) esclarecem, assim como o fenômeno religioso deve permanecer fora do escopo das generalizações científicas, acreditamos que a Religião não pode se confundir com a prática científica em sentido estrito, haja vista suas inúmeras diferenças já descritas, inclusive metodológicas, metafísicas e epistemológicas (LACEY, 1996; MAHNER; BUNGE, 1996a, 1996b; WOOLNOUGH, 1996). Desse modo, entendemos ser inapropriado equiparar o conhecimento científico ao conhecimento religioso no ensino de ciências, mesmo que possamos utilizar o diálogo para fazer a ponte entre eles.

\section{CONSIDERAÇÕES FINAIS}


Edição Especial: I SSAPEC - Simpósio Sul-Americano de Pesquisa em Ensino de Ciências ISSN: 2595- $4520 \quad$ Vol. 4, n. 3. 2021

Investigações a respeito de como as ideias prévias dos estudantes se relacionam com as ideias científicas, cada vez mais se mostram favoráveis ao entendimento de que ideias contraditórias podem coexistir em um mesmo modelo ou explicação sobre determinado objeto de estudo. No caso da relação entre as crenças religiosas e as concepções científicas, essa assertiva se mostra clara quando se verifica que a aplicação dos conhecimentos em cada um dos domínios pode ser dada a partir de seu contexto de aplicação (MORTIMER, 1993, 1996; COBERN, 1993, 1996).

Tendo em vista as diferentes maneiras de se categorizar a relação entre Ciência e Religião (Conflito, Síntese e Diálogo), entendemos que os caminhos mais profícuos são aqueles que incorporam a dialogicidade dos saberes, visto que a busca permanente por uma escola que se propõe laica, democrática e plurirreligiosa deve permitir formas pedagógicas que se adequem ao giro dialógico próprio da sociedade informacional.

Abordagens teóricas pautadas em bases dialógicas da aprendizagem têm contribuído de forma bastante pertinente para uma perspectiva mais científica dos processos pedagógicos (AUBERT et al., 2008), exatamente porque na educação científica os procedimentos fundamentais são aqueles que permitem a investigação e o debate de fatos e ideias de forma negociada. Portanto, entendemos que a abordagem ancorada no diálogo contribui para a escolha de estratégias de ensino que lidam com os obstáculos de aprendizagem sob uma perspectiva científica, democrática e plural.

\section{REFERÊNCIAS}

ALMEIDA, D. F Concepções de alunos do ensino médio sobre a origem das espécies.

Ciência \& Educação, Bauru, v. 18, n. 1, p. 143-154, 2012. Disponível em: https://www.scielo.br/scielo.php?pid=S1516-

73132012000100009\&script=sci_abstract\&tlng=pt. Acesso em: 05 jan. 2020.

AUBERT, A. et al. Aprendizaje dialógico en la Sociedad de la Información. Barcelona, Hipatia Editorial, 2008.

BACHELARD, Gaston. Coleção os pensadores. São Paulo: Abril Cultural, 1978.

BARBOUR, I. G. Quando a ciência encontra a religião. São Paulo: Cultrix, 2004.

BISHOP, B.; ANDERSON, C. W. Students' conceptions of natural selection and its role in evolution. Journal of Research in Science Teaching, 27, 415-427, 1990. 
Edição Especial: I SSAPEC - Simpósio Sul-Americano de Pesquisa em Ensino de Ciências

ISSN: 2595- $4520 \quad$ Vol. 4, n. 3. 2021

Disponível em: https://onlinelibrary.wiley.com/doi/abs/10.1002/tea.3660270503. Acesso em: 05 jan. 2020.

CARAVITA, S.; HALLDÉN, O. Re-framing the problem of conceptual change. Learning and instruction, v. 4, n. 1, p. 89-111, 1994. Disponível em: https://www.sciencedirect.com/science/article/abs/pii/0959475294900205. Acesso em: 05 jan. 2020.

CHI, M. T. H. Conceptual change within and across ontological categories: Examples from learning and discovery in science. To appear in R. Giere (Ed.). Cognitive models of Science: Minnesota Studies in the philosophy of Science. University of Minnesota Press, 1991.

COBERN, W. W. Contextual constructivism: The impact of culture on the learning and teaching of science. Scientific Literacy and Cultural Studies Project, p. 51-69, 1993. Disponível em: https://scholarworks.wmich.edu/cgi/viewcontent.cgi?article=1010\&context=science_slc sp. Acesso em: 05 jan. 2020.

COBERN, W. W. Point: Belief, understanding, and the theaching of evolution. Journal of Research in Science Teaching, v. 31, n. 5, p. 583-590, 1994. Disponível em: https://www.researchgate.net/publication/229638680_Point_Belief_Understanding_and _the_Teaching_of_Evolution. Acesso em: 05 jan. 2020.

COBERN, W. W. Worldview theory and conceptual change in science education. Science Education, v. 80, n. 5, 579-610, 1996. Disponível em: https://onlinelibrary.wiley.com/doi/abs/10.1002/\%28SICI\%291098-

237X\%28199609\%2980\%3A5\%3C579\%3A\%3AAID-SCE5\%3E3.0.CO\%3B2-8.

Acesso em: 05 jan. 2020.

CUNHA, L. A. Ensino religioso nas escolas públicas: a propósito de um seminário internacional. Educação \& Sociedade, Campinas, v. 27, n. 97, p. 1235-1256, set./dez. 2006. Disponível em: http://www.scielo.br/pdf/es/v27n97/a08v2797.pdf. Acesso em: 10 jan. 2020.

CUNHA, L. A. Educação e Religiões: a descolonização religiosa da Escola Pública. Belo Horizonte: Mazza Editora, 2013.

DEMASTES-SOUTHERLAND, S., SETTLAGE, J.; GOOD, R. Students' conceptions of natural selection and its role in evolution: Cases of replication and comparison. Journal of Research in Science Teaching, n. 32, p. 535-550, 1995. Disponível em: Recebido em: 18/01/2021

Aceito em: 24/02/2021 
Edição Especial: I SSAPEC - Simpósio Sul-Americano de Pesquisa em Ensino de Ciências

ISSN: 2595- $4520 \quad$ Vol. 4, n. 3. 2021

https://www.researchgate.net/publication/229664960_Students'_conceptions_of_natural _selection_and_its_role_in_evolution_Cases_of_replication_and_comparison. Acesso em: 05 jan. 2020.

DEMBSKI, W. A. Intelligent Design: the bridge between science \& theology. Downers Grove, Illionois: IVP Academic, 1999.

DORVILLÉ, L. F. M. Religião, escola e ciência: conflitos e tensões nas visões de mundo de alunos de uma licenciatura em ciências biológicas. 2010. 357 f. Tese de Doutorado. Tese (Doutorado) - Universidade Federal Fluminense, Niterói, 2010.

DUSCH, R. A. Editorial Policy Statement and Introduction. Science Education, v. 78, n. $3, \quad$ p. 203-208, $1994 . \quad$ Disponível em: https://onlinelibrary.wiley.com/doi/10.1002/sce.3730780302. Acesso em: 05 jan. 2020. EBENEZER, J. V.; GASKELL, P. James. Relational conceptual change in solution chemistry. Science Education, v. 79, n. 1, p. 1-17, 1995. Disponível em: https://onlinelibrary.wiley.com/doi/abs/10.1002/sce.3730790102. Acesso em: 05 jan. 2020.

EL-HANI, C. N.; BIZZO, N. M. V. Formas de construtivismo: teoria da mudança conceitual e construtivismo contextual. Ens. Pesqui. Educ. Ciênc. (Belo Horizonte), vol.4 n.1, Belo Horizonte Jan./June 2002. Disponível em: http://www.scielo.br/pdf/epec/v4n1/1983-2117-epec-4-01-00040.pdf. Acesso em: 05 jan. 2020.

EUVÉ, F. Darwin et le christianisme, vrais et faux débats. Paris: Buchet Chastel, 2009.

FIGUEIREDO, P. S; SEPULVEDA, C. Religião e ciência: o que as interações discursivas nos mostram sobre os desafios de um ensino de biologia dialógico. Investigações em Ensino de Ciências, v. 23, n. 2, pp. 228-255, 2018. Disponível em: https://www.if.ufrgs.br/cref/ojs/index.php/ienci/article/view/1064. Acesso em: 05 jan. 2020.

FLECHA, R. Compartiendo palavras: el aprendizaje de las personas adultas a través del diálogo. Barcelona: Editorial Paidós, 1997.

GAULD, C. Models, meters and memory. Research in Science Education, v. 16, 4954, 1986. Disponível em: https://link.springer.com/article/10.1007/BF02356817. Acesso em: 05 jan. 2020. 
Edição Especial: I SSAPEC - Simpósio Sul-Americano de Pesquisa em Ensino de Ciências

ISSN: 2595- $4520 \quad$ Vol. 4, n. 3. 2021

GUNSTONE, R. F.; CHAMPAGNE, A. B.; KLOPFER, L. E. Instruction for understanding: A case study. Australian Science Teachers Journal, v. 27, n. 3, pp. 27 32 , 1981.

Disponível

em:

https://www.researchgate.net/profile/Richard_Gunstone/publication/297710644_Instruc tion_for_understanding_A_case_study/links/56e0adb008ae979addf0fb2b/Instructionfor-understanding-A-case-study.pdf. Acesso em: 05 jan. 2020.

HABERMAS, J. Teoria de la acción comunicativa. Madrid: Taurus, 1987.

HAUGHT, J. F. Deus após Darwin: uma teologia evolucionista. Trad. Vera Whately $2^{\mathrm{a}}$ ed. Rio de Janeiro: José Olympio, 2006.

HEWSON, P.W.; THORLEY, R. The conditions of conceptual change in the classroom. International Journal of Science Education, v. 11, n. 5, p. 541-553, 1989. Disponível em: https://www.tandfonline.com/doi/abs/10.1080/0950069890110506. Acesso em: 05 jan. 2020.

JONES, S. L. A constructive relationship for religion with the science and profession of psychology: Perhaps the boldest model. American Psychologist, n. 49, p. 184-199, 1994. Disponível em: https://psycnet.apa.org/record/1994-29392-001. Acesso em: 05 jan. 2020.

LACEY, H. Sobre as relações entre ciência e religião. Ciência e Educação, v. 5, n. 2, p. $143-153,1996$.

LINDER, C. J. A challenge to Conceptual Change. Science Education, v. 77, n. 3, p. 293-300, 1993.

Disponível

em:

https://onlinelibrary.wiley.com/doi/abs/10.1002/sce.3730770304. Acesso em: 05 jan. 2020.

MAHNER, M.; BUNGE, M. Is religious education compatible with science education?. Science \& Education, v. 5, n. 2, p. 101-123, 1996a. Disponível em: https://link.springer.com/article/10.1007/BF00428612. Acesso em: 05 jan. 2020.

MAHNER, M.; BUNGE, M. The incompatibility of science and religion sustained: a reply to our critics. Science \& Education, v. 5, n. 2, p. 189-199, 1996b. Disponível em: https://link.springer.com/article/10.1007/BF00428619. Acesso em: 05 jan. 2020.

MATTHEWS, M. R. Science Teaching: The Role of History and Philosophy of Science. New York: Routledge, 1994.

McGRATH, A. E. Fundamentos do diálogo entre ciência e religião. Trad. Jaci Maraschin. São Paulo: Loyola, 2005.

Recebido em: 18/01/2021

Aceito em: 24/02/2021 
MELlO, R. R.; BRAGA, F. M; GABASSA, V. Comunidades de Aprendizagem: outra escola é possível. São Carlos: EdUFSCar, 2014.

MORTIMER, E. F. Studying conceptual evolution in the classroom as conceptual profile change. In: Proceedings of the Third International Seminar on Misconceptions and Educational Strategies in Science and Mathematics. Ithaca, NY: Misconceptions $1993 . \quad$ Trust, Disponível em: http://www.mlrg.org/proc3pdfs/Mortimer_ConceptualProfile.pdf. Acesso em: 05 jan. 2020.

MORTIMER, E. F. Construtivismo, mudança conceitual e ensino de ciências: para onde vamos? Investigações em ensino de ciências, v. 1, n. 1, p. 20-39, 2016. Disponível em: https://www.if.ufrgs.br/cref/ojs/index.php/ienci/article/view/645. Acesso: 05 jan. 2020. POOLE, M. '...For more and better religious education'. Science \& Education, v. 5, n. 2, p. 165-174, $1996 . \quad$ Disponível em: https://link.springer.com/article/10.1007/BF00428616. Acesso em: 05 jan. 2020.

POSNER, G. J. et al. Accommodation of a scientific conception: Toward a theory of conceptual change. Science Education, v.66, n.2, p. 211- 227, 1982. Disponível em: https://onlinelibrary.wiley.com/doi/abs/10.1002/sce.3730660207. Acesso em: 05 jan. 2020.

ROLDÃO, M. C. Estratégias de ensino: o saber e o agir do professor. Vila Nova de Gaia, PT: Fundação Manuel Leão, 2010.

RUSSELL, C. A. Correntes Cruzadas: interações entre a ciência e a fé. São Paulo: Hagnos, 2004.

SEPULVEDA, C. A relação entre religião e ciência na trajetória profissional de alunos protestantes da licenciatura em ciências biológicas da universidade estadual de feira de Santana, 2003. Dissertação de Mestrado - Universidade Federal da Bahia, Bahia, 2003.

SETTLAGE, J. Conceptions of natural selection: A snapshot of the sense-making process. Journal of Research in Science Teaching, v. 31, 449-457, 1994. Disponível em:

https://www.researchgate.net/publication/227775565_Conceptions_of_natural_selection _A_snapshot_of_the_sense-making_process. Acesso em: 05 jan. 2020. 
Edição Especial: I SSAPEC - Simpósio Sul-Americano de Pesquisa em Ensino de Ciências

SETTLE, T. Applying scientific openmindedness to religion and science education. Science \& Education, v. 5, n. 2, p. 125-141, 1996. Disponível em: https://link.springer.com/article/10.1007/BF00428613. Acesso: 05 jan. 2020.

TURNER, H. Religion: impediment or saviour of science? Science \& Education, v. 5, n. $2, \quad$ p. 155-164, 1996. Disponível em: https://link.springer.com/article/10.1007/BF00428615. Acesso: 05 jan. 2020.

WHITE, T. R.; GUNSTONE, R. F. Metalearning and conceptual change. International Journal of Science Education, v. 11, n. 5, p. 577-586, 1989. Disponível em: https://www.tandfonline.com/doi/abs/10.1080/0950069890110509. Acesso em: 05 jan. 2020.

WOOLNOUGH, B. On the fruitful compatibility of religious education and science. Science \& Education. v. 5, n.2, p. 175-183, 1996. Disponível em: https://link.springer.com/article/10.1007/BF00428617. Acesso em: 27 dez. 2020. 